\title{
SCNS.06. Oral gabapentin treatment accentuates nerve and peripheral inflammatory responses following experimental nerve constriction in Wistar rats.
}

\author{
CÂMARA, C.C. a,b, RAMOS, H.F., SILVA, A.P., ARAÚJO, C.V. ${ }^{c}$, GOMES, A.S. e, VALE, \\ M.L. e, BARBOSA. A.L.R.e, ORIÁ, R.B. ${ }^{c, d}$
}

aLaboratory of Experimental Neurophysiology, Department of Physiology and Pharmacology, School of Medicine, Federal University of Ceará, Fortaleza, CE, Brazil bLaboratory of Neurophysiology, School of Veterinary, Federal and Rural University of the SemiArid, Mossoro, RN, Brazil

'Laboratory of Tissue Healing, Ontogeny and Nutrition, Institute of Biomedicine of the Brazilian SemiArid, Federal University of Ceara, Fortaleza, CE, Brazil

${ }^{d}$ Department of Morphology, School of Medicine, Federal University of Ceara, Fortaleza, CE, Brazil

eLaboratory of Inflammation and Cancer, Department of Physiology and Pharmacology, School of Medicine, Federal University of Ceara, Fortaleza, CE, Brazil

Introduction: Gabapentin (GBP) is an anti-convulsive drug often used as analgesic to control neuropathic pain. Objectives: This study aimed at evaluating whether oral GBP treatment could improve nerve inflammation response after sciatic nerve constriction in association with selected pain and motor spontaneous behavior assessments in Wistar rats. Methods: We evaluated nerve myeloperoxidase (MPO) and inflammatory cytokines on the 5th day post-injury, time in which nerve inflammation is ongoing. In addition, the role of GBP on carrageenan-induced paw edema and peritoneal cell migration was analyzed. GBP was given by gavage at doses of 30,60 and $120 \mathrm{mg} / \mathrm{kg}, 60 \mathrm{~min}$ prior to chronic constriction of the sciatic nerve (CCSN) and during 5days post-injury, 12/12 h. CCSN animals treated with saline were used as controls and for behavioral and inflammation assessments untreated sham-operated rats were also used. On the 5th day, GBP (60and $120 \mathrm{mg} / \mathrm{kg}$ ) alleviated heat-induced hyperalgesia and significantly increased delta walking scores in CCSN animals, the latter suggesting excitatory effects rather than sedation. GBP $(60 \mathrm{mg} / \mathrm{kg})$ significantly increased nerve MPO, TNF-alpha, and IL-1beta levels, comparing with the saline group. GBP $(120 \mathrm{mg} / \mathrm{kg})$ reduced the anti-inflammatory cytokine IL-10 nerve levels compared with the CCSN saline group. Results: Furthermore, GBP (60 and 120 $\mathrm{mg} / \mathrm{kg}$ ) increased carrageenan-induced paw edema and peritoneal macrophage migration compared with the CCSN saline group. Conclusions: Altogether our findings suggest that GBP accentuates nerve and peripheral inflammatory response, however confirmed its analgesic effect likely due to an independent CNS-mediated mechanism, and raise some concerns about potential GBP inflammatory side effects in widespread clinical use.

CÂMARA, C.C.; RAMOS, H.F.; SILVA, A.P.; ARAÚJO, C.V.; GOMES, A.S.; VALE, M.L.; BARBOSA. A.L.R.; ORIÁ, R.B. 2013. Oral gabapentin treatment accentuates nerve and peripheral inflammatory responses following experimental nerve constriction in Wistar rats, p.16. In: Oriá, Reinaldo Barreto; Andrade, Geanne Matos de; Bruin, Veralice Meireles S. de.

I International Symposium in Neuroscience Meeting [Blucher Neuroscience Proceedings n.1 v.1]. São Paulo: Blucher, 2014, http://dx.doi.org/10.5151/isnm-sine11 